\title{
DECOMPOSITION OF SBM TECHNICAL EFFICIENCY OF THE SECONDARY EDUCATION SYSTEM INTO RADIAL EFFICIENCY AND MIX EFFICIENCY: A STATE-WISE ANALYSIS IN INDIA
}

\author{
Dr. Rangalal Mohapatra
}

Assistant Professor, Dept. Economics, Sikkim University, Gangtok Sikkim, 737901

rangalalm333@gmail.com, rmohapatra@cus.ac.in

\begin{abstract}
This paper is an attempt to decompose the non-radial technical efficiency in terms of a scalar called SBM of efficiency (input Oriented) of the performances of 23 states of India in the $10^{\text {th }}$ class examination. Applying CCR, BCC and SBM models for five inputs and two outputs obtained from the Statistics of school education, 2010-11 (MHRD, Govt. of India), the efficiency scores were computed and the SBM efficiency scores were decomposed into technical efficiency, pure technical efficiency, scale efficiency and mix efficiency. The mean TE scores are 0.86 with a SD of 0.17 and mean PTE score of 0.92 with SD of 0.09 . Out of 23 states 10 states achieved MPSS status and 13 states were in efficient. As per the SBM score, out of 23 states 10 states are fully SBM efficient with score equals to 1 and hence they are TE, PTE and Scale efficient implying most productive scale size. But more than half of the states (13) are inefficient with Assam being the lowest performer (0.18) followed by Kerala (0.22), Rajasthan (0.25) and Chhattisgarh (0.31). The states with low SBM score due to PTE and MIX are Assam, Karnataka, Maharastra, Odisha, Rajasthan and UP. The states having low score due to low PTE and low SE are Assam and Karnataka. The states with low SBM score due to low PTE, MIX and SE are Assam and Karnataka. The study emphasizes, merger of small private schools, increase in the appointment of both trained male and female teachers, Creation of more class rooms. One important implication of the result is that the state should focus more on the giving special coaching to the SC/ST students and the girl students especially in English, math and science.
\end{abstract}

\section{Indexing terms/Keywords}

Radial efficiency, Non-radial efficiency, Technical Efficiency, Pure Technical Efficiency, Scale efficiency, Mix efficiency, Slack Based measres, Variable returns to Scale, Education

\section{Academic Discipline And Sub-Disciplines}

Economics, Economics of educational outcome, Efficiency Measurement

\section{SUBJECT CLASSIFICATION}

Economics, Education, JEL Classification C-14, 12-121

\section{TYPE (METHOD/APPROACH)}

Non Parametric Approach-Input oriented DEA under CRS and VRS, SBM Input Oriented DEA under CRS.

\section{Council for Innovative Research}

Peer Review Research Publishing System

Journal: Journal of Social Sciences Research

Vol .7, No.2

jssreditor.cir@gmail.com

www.jssronline.com 


\section{INTRODUCTION}

The crux of the human resource development is that education has to play a significant and interventionist role in correcting and reducing the imbalances in the socio economic fabric of the society. Education for all aims at quality basic education all over the country and seeks to ensure access, retention and quality improvement; the focus on girls education to equalize educational opportunities and eliminate gender disparities. India has a vast population and to capture the potential demographic dividend, to remove the acute regional, social and gender imbalances, the government of India is committed to make concerted efforts for improving the quality of education as mere quantity expansion will not deliver the desired result in view of fast changing domestic and global scenario. As far as the secondary education is concerned, Rastriya Madhyamik Siksha Abhiyan was launched in March 2009 with the objective to enhance access to secondary education and to improve its quality. It envisaged at achieving an enrolment rate of 75 from 52.26 in 2005-06 at secondary stage within five years by providing a secondary school within a reasonable distance of any habitation (Table- 1 shows the number of Schools). The other objectives include improving quality of education impaired at secondary level through making all secondary schools confirm to the prescribed norms removing gender socio economic and desirability barriers providing universal access to secondary level education by 2017. Improvement in the quality will be through: appointment of additional teachers to reduce pupil teacher ratio to $30: 1$; to focus on Science Math and English education; in service training of teachers; ICT enabled education; curriculum reform and teaching learning reform. Equity aspect will be addressed through special focus on micro planning preference to areas concentrated with SC/ST/Minorities and more female teacher etc.

Table-1: No of High Schools

\begin{tabular}{|l|l|l|}
\hline Year & No of High school & No of Boards \\
\hline $1950-51$ & 7416 & 7 \\
\hline $1970-71$ & 37051 & 37 \\
\hline $1990-91$ & 82576 & 44 \\
\hline $2000-01$ & 126047 & 39 \\
\hline
\end{tabular}

Source: Reports of Ministry of Human Resource Development, Various Issues

As per the constitution of India, school education was originally a state subject- that is the states had complete authority in deciding policies and implementing them. The role of Government of India was limited to coordination and deciding on the standard of higher education. The constitutional amendment 1976 put education in concurrent List. The National Policy on Education, 1986 and the Programme of Action (PoA), 1992 envisaged free and compulsory education of satisfactory quality for children all below 14 years before the $21^{\text {st }}$ century. Besides CBSE and ICSE schools, each school has its own department of education that runs its own school system within its own text books and evaluation system. The curriculum, pedagogy and evaluation methods are largely decided by the SCERT in the state, following the National guidelines followed by NCERT. Table -2 shows the percentage of schools under different management. Comparatively, the private unaided schools have increased from $5.59 \%$ in 1973 to $34.56 \%$ in 2006-07. But the total private schools consisted of more than $63 \%$.

Table-2: Percentage of Secondary Schools under Different Management

\begin{tabular}{|l|l|l|l|l|l|}
\hline year & Govt bodies & Local body & Govt+local & Pvt aided & Pvt unaided \\
\hline $1973-74$ & 26.54 & 10.85 & 37.39 & 57.02 & 5.59 \\
\hline $1993-94$ & 37.76 & 9.29 & 47.05 & 37.78 & 15.17 \\
\hline $2003-04$ & 33.33 & 8.44 & 42.75 & 29.30 & 29.60 \\
\hline $2006-07$ & 31.16 & 6.17 & 37.32 & 28.12 & 34.56 \\
\hline
\end{tabular}

Source: Department of Higher Education, MHRD, GOI.

Secondary education is a crucial stage in the educational hierarchy as it prepares the young person's for higher education and also the world for the work. The Government of India's intervention in secondary education is at two levels: through apex national bodies and through centrally sponsored scheme such as boarding and hostel facilities for girls student of secondary and higher secondary school, information and communication technology schools and quality improvement in the school.

Improving the efficiency of the schools is a growing concern of educational planners and managers in recent years. The shift of the attention towards strategies which focus on school functioning rather than the overall education system is inspired by several considerations. Firstly, reforms have very often targeted the provision of the inputs in the system rather than the process of teaching and decision making in particular in schools which are crucial in explaining differences in quality. Secondly, many reforms in the past tried to focus on isolated components of the system for instance, teachers or text book. However, improving the efficiency of the individual component does not automatically lead to improving an organization. Processes are contextual and their improvement depends on the capacity of each school to become an 
effective organization. Thirdly, reforms were not adopted to the very varied means of the individual schools characterized as they were by general, system wise strategy. Educational sector is substantially varied. It is therefore necessary to use extreme care in constructing "performance indicators" for efficiency analysis. Two issues are primary importance: first, institutions operate under different conditions and environments, which are often not simply explained. Second, the educational production sector contains many inputs and output.

Despite a huge rise in the number of high schools at All India level (from 7416 in 1950-51 to a 126047 in 2000-01) and increment in the enrolment of students, increase in student teacher ratio, recruitment of more male and female teachers, all the states in India do not perform in an uniform manner. Hence, keeping in view that secondary school education (Class 10) is indeed important in building the career, the present paper has made an attempt to measure the level of efficiency of the states as far as the performance in the $10^{\text {th }}$ class result is concerned ${ }^{1}$. The technical efficiency (TE) scores obtained by each state inform the level of efficiency that can be improved upon to achieve scores equal to the best performers. The decomposition of TE scores into Pure Technical Efficiency (PTE) and Scale Efficiency (SE) has been made to know the sources of inefficiency at individual state level. Further, non-radial efficiency (Input Oriented Slack based Measure of efficiency (SBM) introduced by Tone $(1997,2001)$ ) is used to estimate the difference between SBM efficiency scores and the TE scores which will indicate the extent of mix efficiency (MIX). The equality between SBM score and the TE score indicates no MIX inefficiency.

\section{LITERATURE REVIEW}

Created by Charnes Cooper and Rhodes (1978), Data Envelopment Analysis was developed for application to non- profit entries to identify inefficiencies of inputs and outputs. The first application of DEA was to public schools in the evaluation of Programme Fellow through (Charnes, Cooper Rhodes, 1981). Since then DEA has been greatly extended and advanced in its method of specialization. DEA has been applied to a variety of other non-profit entities (Emrouznejad and Thanassoulis, 1996).

There are a number of important DEA studies looking at the efficiency of higher education, including Ahn (1987), Ahn, Arnold, Charnes and Cooper (1989) and Avkiran (2001). Recent country specific paper include studies looking at the efficiency of higher education in UK (Johnes, 2006) Australia (Abott and Doucouliagos, 2003) and China (Ng and Li, 2010), Rhodes and Southwick (1986) compiled data from 1979-80 for 96 public and 54 private institutions to perform their analysis. For inputs they used the number of full Professors, no of Assistant Professors no of associate professors, dollars spent on maintenance and dollar spent on libraries. For output they used undergraduate enrolment. Their results indicate that public institutions of higher learning are less efficient than private ones. In studying the technical efficiency of IITs and IISc. using SFA and DEA models Kulashrestha and Nayak (2015) found that TE varies across the institutions and highlights the need for strengthening the knowhow. Other applications of DEA to measure efficiency in higher education include Buston and Phimister (1995), who have applied DEA to evaluate the efficiency of a set of "core Journals". Haksever and Muragishi (1998) have used output oriented CCR for the top 20 MBA programmes in USA to analyze early 1990s data from business week and found no efficiency differences between the above two groups of MBA programmes.

The international literature contains several studies in many countries which mostly apply Data Envelopment analysis. Ahn et. al. (1998) compared higher US higher education institution aimed at research using three inputs and three output factors. Public universities achieved greater levels of efficiency than private facilities. In a separate study, Rhodes and Southwick (1986), contrast the efficiency of 96 public and 54 private universities in United States (US), applying DEA models with five inputs and six output factors. Results indicated that efficiency in private institutions at that time was higher than public facilities. Breu and Raab (1994) used DEA to access efficiency in 25 of the best universities. Their findings confirm DEA as an appropriate method for measuring efficiency in higher education. SARRICO et al.,(1997) evaluated 90 higher education facilities in the Unites Kingdom in three categories: (i) government; (ii)institutions: department staffs and students and (iii) potential students. The authors used DEA methodology to determine efficiency levels and compared these with a local ranking and found that DEA indicated better efficiency. Forsund and Kalhagen (1999) investigated efficiency in Norweigian regional facilities in 1994 to 1996. Some institutions were found to be efficient with regard to education services, while inefficient facilities showed significant variation between inefficiency level. Additionally productivity improved during the year studied. Thurlow and Field (2003) analysed the technical efficiency of 45 British Universities from 1980-81 to 1992-93. The study recorded a significant increase in technical efficiency during this time. Research by Afonso and Santos (2005) estimated efficiency of public universities in Portugal in 2003. Findings indicate a mean efficiency index of approximately 55.3 and 67.8 respectively among facilities investigated. Abbot and Doucouliagos (2003) studied technical efficiency scale of Australian University system. Results point to performance homogeneity for the whole university system. Joumady and Ris (2004) applied DEA methodology to measure efficiency differences in a group of 210 higher education institutions from 8 European countries using a sample of students graduated for more than three years and efficiency varied in accordance with the models used. Souza and Ramos (1997) analyzed the performance of federal higher education facilities in Brazil using DEA and found that 39.1 of the institutions evaluated achieved maximum efficiency while 6.5 were among the least efficient. In his doctorate thesis Belloni (2001) evaluated the productive efficiency performance of 33 Brazilian Federal Universities using DEA methodologies. In contrast to Souza and Ramos (1997) only 6 of 33 federal universities investigated were considered technically efficient. Oliveira and Turrioni (2005) assessed the relative efficiency of federal institutions of higher education (IFES). Five out of 19 institutions were found to be technically inefficient.

\footnotetext{
${ }^{1}$ Out of 29 states only 23 states are considered because of the unavailability of required secondary data accessed from the Statistics of School Education (2010-11), Government of India, MHRD, Bureau of Planning and Monitoring and Statistics, New Delhi, 2012.
} 


\section{METHODOLOGY}

In order to study measure the efficiency scores the states of India are taken into consideration. Since all the states of India follow a uniform pattern of syllabus for class 10, each state is considered as a Decision making Unit as far as the inputs used and outputs produced are concerned. A total of 23 states have been considered with five inputs and two outputs. The inputs used for each state are: number of students appeared class 10 board examination (SA), number of private unpaid schools (PUS), Scheduled Tribe Student Enrolment (STSE), Pupil Teacher ratio (PTR) and Number girls per 1000 boys (GPTB). The outs considered are percentage of students passed with more than $60 \%$ marks (PSMS) and percentage of students passed with $50 \%$ and $60 \%$ marks (PSFS). ${ }^{2}$

\section{A- Technical Efficiency:}

The CCR model was initially proposed by Charnes, Cooper and Rhodes in 1978. The input oriented CCR model by taking into all input excess and output shortfalls can be written in the following two stage LP problem (Cooper et.al., 2000).

\section{$\left(D L P_{0}\right)$}

$$
\begin{aligned}
& \text { Phase I objective Min } \theta \\
& \text { Phase II Objective Min -es }{ }^{-}-\mathrm{es}^{+} \\
& \text {Subject to } \quad \theta \mathrm{x}_{0}=\mathrm{X} \lambda+\mathrm{es}^{-} \\
& \mathrm{y}_{0}=\mathrm{Y} \lambda-\mathrm{es}^{+} \\
& \theta \geq 0, \lambda \geq 0, s^{-} \geq 0, s^{+} \geq 0
\end{aligned}
$$

If an optimal solution $\left(\theta^{*}, \lambda^{*}, \mathrm{~s}^{-*}, \mathrm{~s}^{+^{*}}\right)$ of the two LPs above satisfies (i) $\theta^{*}=0$ and zero slacks $($ ii) $)\left(\mathrm{s}^{-*}=0, \mathrm{~s}^{+}=0\right)$ then the $\mathrm{DMU}_{0}$ is called CCR efficient. The first of these two is called radial efficiency. It is also referred to as technical efficiency because the value of $\theta^{*}<1$ means that all inputs can be simultaneously reduced without altering the mix in which they are utilized.. Hence, the inefficiency associated with the non zero slack is referred to as " mix inefficiencies" The conditions (i) and (ii) taken together describe together what is called "Pareto Koopmans" or strong efficiency. The extension to the CCR model is the BCC (Banker, Charnes Cooper ) model. The model has its production frontiers spanned convex hull of the existing DMUs. The frontiers have piecewise linear and concave characteristics which leads to variable returns to scale characterized by increasing return followed by decreasing return and the constant return occurring at the point where the transition from the first to second segment is made. The input oriented BCC model evaluates the efficiency of $\mathrm{DMU}_{0}$ by solving the following linear program

$\begin{array}{ll}\left(\mathrm{BCC}_{0}\right) \quad \text { Min } & \theta_{\mathrm{B}} \\ \text { subject to } & \theta_{\mathrm{B}} \mathrm{X}_{0}-\mathrm{X} \lambda \geq 0 \\ & \mathrm{Y} \lambda \geq \mathrm{y}_{0} \\ & \mathrm{E} \lambda=1 \\ & \lambda \geq 0\end{array}$

The primal $\left(\mathrm{BCC}_{0}\right)$ problem is solved using a two phase procedure similar to the CCR case.. In the first phase we minimize $\theta_{\mathrm{B}}$ and in the second phase we maximize the sum of input excesses and output shortfalls keeping $\theta_{\mathrm{B}}=\theta^{*}$. Notice that the $\theta_{B}^{*}$ is not less than the $\theta_{C C R}^{*}$ since $B C C_{0}$ imposes an additional restriction $E \lambda=1$ so it's feasible region is a subset of the feasible region of CCR model. If an optimal solution $\left(\theta_{B}^{*}, \lambda^{*}, s^{-*}, s^{+*}\right)$ satisfies $\theta_{B}^{*}=1$ and no slack $\left(, s^{*^{*}}=0, s^{+*}=0\right)$ then the DMU is called BCC efficient otherwise not. The discrepancy between $\theta^{*} \mathrm{CCR} \theta^{*}$ BCc gives Scale Efficiency ie

\section{B- Mix Efficiency:}

$$
S E=\frac{\theta \mathrm{CCR}^{*}}{\theta \mathrm{BCC}^{*}}
$$

Out of the two types of efficiency measures e radial and non-radial, the non radial measure of efficiency is called Slack Based Measure of Efficiency (SBM). The input Oriented SBM model is

$$
\begin{gathered}
\left(\mathrm{SBM}_{\mathbb{N}}\right) \operatorname{Min} \quad \rho_{\mathrm{in}=1-\frac{1}{m} \sum_{i=1}^{m} \overrightarrow{s i} / x i o} \\
\text { Subject to } \quad x o=X \lambda+s^{-} \\
y o=Y \lambda-s^{+} \\
\lambda \geq 0, s^{-} \geq 0, s^{+} \geq 0
\end{gathered}
$$

\footnotetext{
${ }^{2}$ The data are collected from the Statistics of School Education (2010-11), Government of India, MHRD, Bureau of Planning and Monitoring and Statistics, New Delhi, 2012. And Secondary Education in India Where do we Stand? State Secondary Education Report 2010-11 (State Report card, 2010-11), National University of Educational Planning and Administration, New Delhi.
} 
If the optimal solution of $(\mathrm{SBM} \min )$ is $\left(\rho_{i n^{*}}, \lambda^{*} S^{-*}, s^{+*}\right)$ then equality of $\rho_{i n^{*}}=\theta^{*} \mathrm{CCR}$ holds if and only if the input oriented CCR model has zero input slacks for every optimal solution. The strict inequality $\rho_{i n^{*}}<\theta$ cCR holds if the CCR solution reveals an input mix inefficiency. The MIX is defined as

$$
M I X={\frac{\rho \text { in }}{\theta C C R^{*}}}^{*}
$$

So,

input oriented SBM $\left(\rho_{i n^{*}}\right)=$ Radial Technical Efficiency (Radial TE) * MIX

$$
\begin{aligned}
& \text { Hence }\left(\rho_{i n^{*}}\right)=[M I X]{ }^{*}[P T E]{ }^{*}[S E] \\
= & \text { Mix efficiency * Pure Technical efficiency * Scale efficiency }
\end{aligned}
$$

\section{ANALYSIS OF RESULTS}

The above decomposition helps in to interpreting the different components of the non-radial efficiency for each DMU. As per the result (Table-3) obtained by CCR input oriented model under weak efficiency assumption 10 DMUs are fully efficient and performing on the frontier. These DMUs are (Bihar, Goa, Haryana, Himachal Pradesh, Madhya Pradesh, Meghalaya, Nagaland, Tamil Nadu, Tripura, and Uttarakhand). The rest out of 23 states are CCR inefficient. That is (1$\theta^{*}$ CR) percent reduction in inputs can also bring them to produce the same output without changing the input mix proportion. Among all the inefficient DMUs, Assam has the lowest rank (23) implying highly inefficient $\left(\theta^{*} \mathrm{CCR}=0.35\right)$ followed by Kerala $\left(\theta^{*} \mathrm{CCR}=0.51\right)$, Rajasthan $\left(\theta^{*} \mathrm{CCR}=0.65\right)$, Karnataka $\left(\theta^{*} \mathrm{CCR}=0.70\right)$ and Odisha $\left(\theta^{*} \mathrm{CCR}=0.75\right)$. Considering the reference set, it is observed that Uttarakhand is acting as a peer for 11 inefficient DMUs followed by Tamil Nadu ( 9 ), Haryana (6) and Bihar (5). The DMUs falling below the mean $\theta^{*} \mathrm{CCR}$ score $(0.8620)$ are Assam (0.35) Chhattisgarh (0.78), Karnatak (0.70), Kerala (0.51), Maharastra (0.78), Odisha (0.75), Rajasthan (0.65) and UP (0.84). The study confirms to

\begin{tabular}{|c|c|c|c|c|c|c|c|}
\hline$\overline{D M U}$ & $\begin{array}{c}\theta^{*} \mathrm{BCC} \\
\text { (PTE) }\end{array}$ & Rank & $\begin{array}{c}\theta^{*} \mathrm{CCR} \\
\text { (Radial TE) }\end{array}$ & $\begin{array}{c}\theta^{*} \mathrm{CCR} \\
/ \theta_{\mathrm{BCC}}^{*} \\
(\mathrm{SE})\end{array}$ & Rank & RTS & Projection \\
\hline Andhra & 0.91 & 15 & 0.90 & 0.99 & 12 & - & Increasing \\
\hline Assam & 0.71 & 22 & 0.35 & 0.49 & 23 & - & Increasing \\
\hline Bihar & 1.00 & 1 & 1.00 & 1.00 & 1-mpss & Constant & - \\
\hline Chhattisgarh & 0.94 & 14 & 0.78 & 0.83 & 17 & - & Increasing \\
\hline Goa & 1.00 & 1 & 1.00 & 1.00 & 1-mpss & Constant & - \\
\hline Gujarat & 0.89 & 17 & 0.87 & 0.97 & 15 & - & Increasing \\
\hline Haryana & 1.00 & 1 & 1.00 & 1.00 & 1-mpss & Constant & - \\
\hline Himachal & 1.00 & 1 & 1.00 & 1.00 & 1-mpss & Constant & - \\
\hline Jharkhand & 0.96 & 13 & 0.93 & 0.98 & 11 & - & Decreasing \\
\hline Karnataka & 0.86 & 18 & 0.70 & 0.81 & 20 & - & Increasing \\
\hline Kerala & 0.90 & 16 & 0.51 & 0.56 & 22 & - & Increasing \\
\hline MP & 1.00 & 1 & 1.00 & 1.00 & 1-mpss & Constant & \\
\hline Maharastra & 0.79 & 20 & 0.78 & 0.98 & 18 & - & Increasing \\
\hline Manipur & 1.00 & 1 & 0.88 & 0.88 & 14 & Increasing & \\
\hline Meghalaya & 1.00 & 1 & 1.00 & 1.00 & 1-mpss & Constant & \\
\hline Mizoram & 1.00 & 1 & 0.89 & 0.89 & 13 & Increasing & \\
\hline Nagaland & 1.00 & 1 & 1.00 & 1.00 & 1-mpss & Constant & \\
\hline Odisha & 0.78 & 21 & 0.75 & 0.96 & 19 & - & Constant \\
\hline Rajasthan & 0.71 & 23 & 0.65 & 0.92 & 21 & - & Increasing \\
\hline TN & 1.00 & 1 & 1.00 & 1.00 & 1-mpss & Constant & \\
\hline Tripura & 1.00 & 1 & 1.00 & 1.00 & 1-mpss & Constant & \\
\hline
\end{tabular}
the findings of Souza and Ramos (1997; Joumady and Ris (2004) and Doucouliagos, 2003).

Table-3: CCR, BCC and Scale Efficiency Scores with RTS Projection 


\begin{tabular}{|l|l|r|l|l|l|l|l|} 
UP & 0.85 & 19 & 0.84 & 0.99 & 16 & - & Increasing \\
\hline Uttarakhand & 1.00 & 1 & 1.00 & 1.00 & 1 -mpss & Constant & \\
\hline Average & & & 0.862 & 0.92 & & & \\
\hline
\end{tabular}

In case of Assam it can remain CCR efficient if it reduces all its input at least by $35 \%$. This shows that Assam has many private unpaid schools admitting more students as a result the pupil teacher ratio became very high. Similarly the number of Tribal students and no of girls' students per Thousand boys is another indicator for low performance in the outcome of percentage of 1 st division and percentage of $2^{\text {nd }}$ division students.

But under the BCC model (Table-3) (local efficiency). There are 12 DMUs who are operating efficiently. With the local situation they utilize their inputs in the best possible manner. These DMUs are (Bihar, Goa, Haryana, Himachal , MP, Manipur, Meghalaya, Mizoram, Nagaland, TN, Tripura, Uttarakhand). But whenever it comes to global context both Manipur and Mizoram fails to achieve it. Hence, except Manipur and Mizoram, all 10 states achieve most productive Scale Size (MPSS).

Under input oriented BCC model the projection for inefficient states are increasing return to scale except Odisha whose projection is constant Return to Scale. Hence the technical efficient $\theta^{*}$ CCR can be decomposed as a product of Pure Technical Efficiency $\theta^{*}$ BCC and scale efficiency. Hence, scale efficiency $\left(\theta^{*} \mathrm{SE}=\frac{\theta * \mathrm{CCR}}{\theta * \mathrm{BCC}}\right)$ and it lies between 0 and 1 .

Looking at the CCR input output projection result (Table-4), among the inefficient states, Assam could reach to the frontier by reducing the PTR, GPTB, TSE and SA by almost $65 \%$ and a further radial reduction of PUS by $74 \%$. Similarly Kerala can perform on the frontier provided it can radially reduce all of its input by at least $50 \%$ without changing the input mix. Most of the states operating below the frontier show a radial reduction of use of PTR, GPTB and STSE.

Table-4: Input and Output Projection under CCR Model (CRT Assumption)

\begin{tabular}{|c|c|c|c|c|c|c|c|}
\hline $\mathrm{DMU}$ & SA & PUS & STSE & PTR & GPTB & PSMS & PSFS \\
\hline Andhra & -37.17 & -90.08 & -89.13 & -9.74 & -11.23 & 0.00 & 0.00 \\
\hline Assam & -65.96 & -73.79 & -65.06 & -65.06 & -65.06 & 0.00 & 0.00 \\
\hline Bihar & 0.00 & 0.00 & 0.00 & 0.00 & 0.00 & 0.00 & 0.00 \\
\hline Chhattisgarh & -21.51 & -21.51 & -77.99 & -69.06 & -21.51 & 0.00 & 0.00 \\
\hline Goa & 0.00 & 0.00 & 0.00 & 0.00 & 0.00 & 0.00 & 0.00 \\
\hline Gujarat & -14.62 & -72.15 & -13.47 & -22.11 & -13.47 & 0.00 & 0.00 \\
\hline Haryana & 0.00 & 0.00 & 0.00 & 0.00 & 0.00 & 0.00 & 0.00 \\
\hline Himachal & 0.00 & 0.00 & 0.00 & 0.00 & 0.00 & 0.00 & 0.00 \\
\hline Jharkhand & -12.20 & -6.75 & -89.14 & -6.75 & -6.75 & 0.00 & 0.00 \\
\hline Karnataka & -43.19 & -88.61 & -30.38 & -30.38 & -30.38 & 0.00 & 0.00 \\
\hline Kerala & -51.80 & -85.80 & -49.34 & -49.34 & -49.34 & 0.00 & 0.00 \\
\hline MP & 0.00 & 0.00 & 0.00 & 0.00 & 0.00 & 0.00 & 0.00 \\
\hline Maharastra & -76.47 & -89.07 & -22.29 & -22.15 & -22.15 & 0.00 & 0.00 \\
\hline Manipur & -12.12 & -40.92 & \begin{tabular}{|l|}
-12.12 \\
\end{tabular} & -12.12 & -12.12 & 19.66 & 0.00 \\
\hline Meghalaya & 0.00 & 0.00 & 0.00 & 0.00 & 0.00 & 0.00 & 0.00 \\
\hline Mizoram & -10.71 & -46.20 & -21.80 & -22.21 & -12.65 & 0.00 & 0.00 \\
\hline Nagaland & 0.00 & 0.00 & 0.00 & 0.00 & 0.00 & 0.00 & 0.00 \\
\hline Odisha & -48.49 & -91.40 & -90.48 & -25.43 & -34.40 & 0.00 & 0.00 \\
\hline Rajasthan & -54.44 & -81.68 & -34.71 & -34.71 & -34.71 & 0.00 & 0.00 \\
\hline TN & 0.00 & 0.00 & 0.00 & 0.00 & 0.00 & 0.00 & 0.00 \\
\hline Tripura & 0.00 & 0.00 & 0.00 & 0.00 & 0.00 & 0.00 & 0.00 \\
\hline UP & -93.41 & $\begin{array}{l}-94.39 \\
\end{array}$ & \begin{tabular}{|l|}
-15.93 \\
\end{tabular} & -55.72 & \begin{tabular}{|l|}
-15.93 \\
\end{tabular} & 0.00 & 0.00 \\
\hline
\end{tabular}




\begin{tabular}{|c|c|c|c|c|c|c|}
\hline Uttarakhand & 0.00 & 0.00 & 0.00 & 0.00 & 0.00 & 0.00 \\
\hline
\end{tabular}

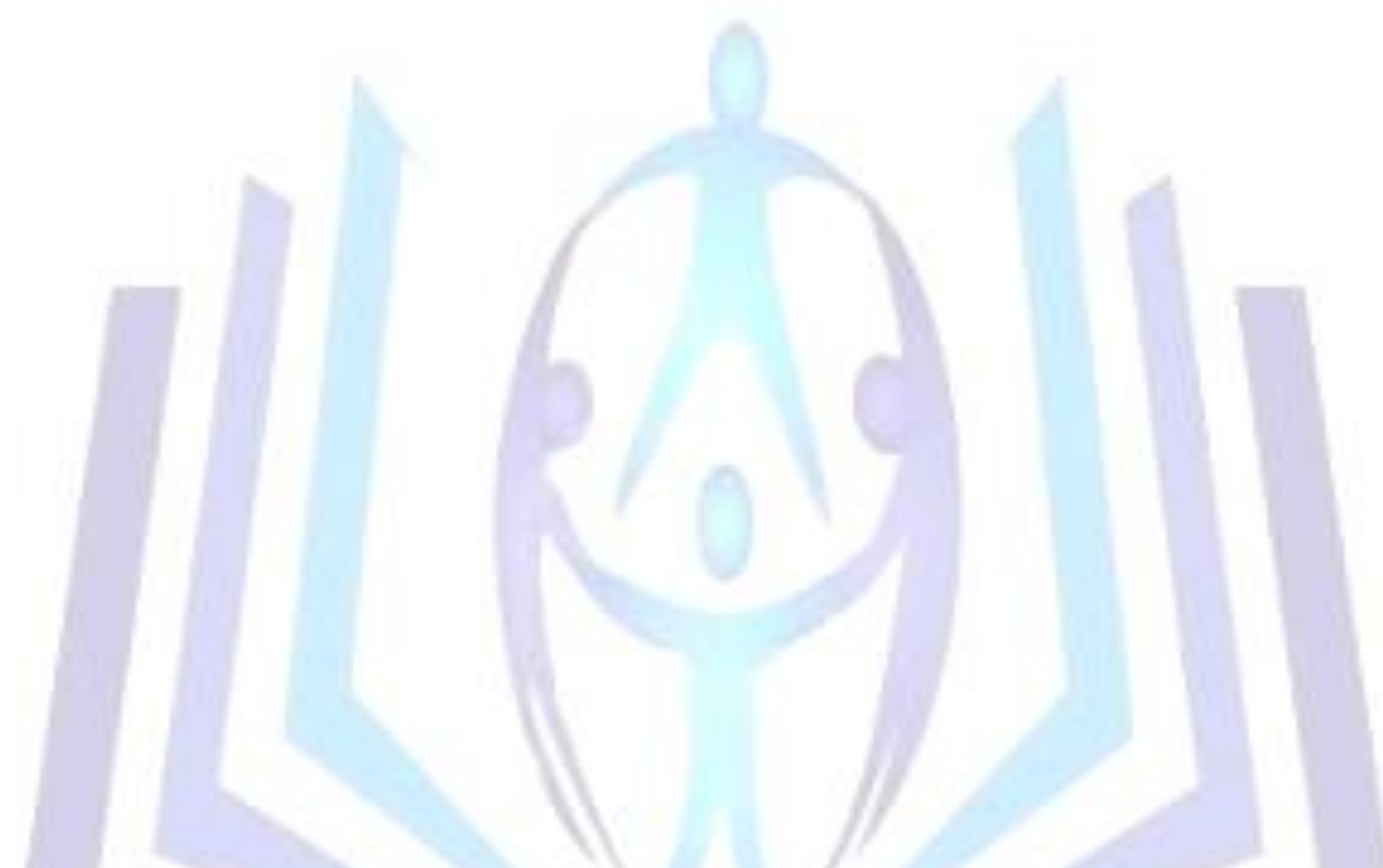

But under the variable returns to Scale (VRS) assumption, the ranking of efficiency of the DMUs have been changed as presented in the Table-3. Rajasthan became the lowest BCC efficient state (0.71) followed by Assam (0.71) Odisha (0.78) The input output projection result shows that (Table-5) Rajasthan can reduce its STSE almost by $30 \%$, PTR by $50 \%$ and GPTG by $30 \%$ without any change in the output. But it has a projection of reduction of SA by $70 \%$ and PUS by $79 \%$. But for Assam, despite the projected reduction in STSE by $73 \%$, PTE by $56 \%$ and GPTB by $30 \%$, it has the possibility to increase the PSMS by $12 \%$ and PSFS by $66 \%$. Because of its inefficient operation of scale, Assam's TE ( $\theta^{*}$ CCR) score became 0.35 which is the product of $\theta^{\star} \mathrm{BCC}$ and $\theta^{\star} \mathrm{SE}(0.71 \times 0.49)$. Similarly Kerala can simultaneously reduce its input mix and can increase its PSMS by $35 \%$ and PSFS by $112 \%$. It means the state uses its available resources quite efficiently. But when compared with the scale of operation of other states, it seems to suffer from scale inefficiency problem. This low SE $\left(\theta^{\star} \mathrm{SE}\right)$ forces Kerala to be a low technically efficient state even though it has high PTE score $\left(\theta^{*} \mathrm{BCC}=0.90\right)$. The BCC input projection result infers that Andhra Pradesh, Assam, Chhatisgarh, Jharkhand and Odisha can reduce the STSE at least by $73 \%$. The State Report Card on Secondary Education, MHRD (2010-11) reveals the fact that The percentage of Schools in the Tribal area in Assam, Chattisgarh, Jharkhandand Odisha are 32.86\%, 39.67\%, $49.43 \%$ and $37.09 \%$ respectively. Further these states have also high percentage of enrolment in rural schools than the enrolment in urban school. Thus the result infers that the huge number of ST enrolment in the state requires additional coaching and tuition in english, math and science.

Similarly, the DMUs such as Andhra Pradesh, Assam, Gujarat, Karnatak, Kerala, Maharastra, Odisha, Rajasthan and Uttar Pradesh could reduce the number of private unpaid schools and hence can reduce the number of students appeared for the class. Since the overall objective is to increase the enrolment in the school, the government should focus on strengthening the school infrastructure, the increasing no of teachers appointed, raising the no. of trained teachers appointed, the internet facility and hostel facilities for the students. For example, in Jharkhand 3.06\% of the schools has single class room and $7 \%$ of the total schools in Chattisgarh has single teacher school. More strangely, $5 \%$ of the total school in Andhra Pradesh has single class room. 
Table-5: Input and Output Projection under BCC Model

\begin{tabular}{|c|c|c|c|c|c|c|c|}
\hline DMU & SA & PUS & STSE & PTR & GPTB & PSMS & PSFS \\
\hline Andhra & -37.56 & -90.03 & -88.86 & -9.02 & -9.02 & 0.00 & 5.90 \\
\hline Assam & -94.17 & -64.36 & -72.67 & -56.00 & -28.74 & 12.94 & 65.96 \\
\hline Bihar & 0.00 & 0.00 & 0.00 & 0.00 & 0.00 & 0.00 & 0.00 \\
\hline Chhattisgarh & -5.83 & -5.83 & -81.10 & -62.54 & -5.83 & 0.00 & 3.51 \\
\hline Goa & 0.00 & 0.00 & 0.00 & 0.00 & 0.00 & 0.00 & 0.00 \\
\hline Gujarat & -21.93 & -71.63 & -10.98 & -23.38 & -10.98 & 0.00 & 0.00 \\
\hline Haryana & 0.00 & 0.00 & 0.00 & 0.00 & 0.00 & 0.00 & 0.00 \\
\hline Himachal & 0.00 & 0.00 & 0.00 & 0.00 & 0.00 & 0.00 & 0.00 \\
\hline Jharkhand & -36.45 & -4.47 & -79.42 & -4.47 & -4.47 & 0.00 & 0.00 \\
\hline Karnataka & -60.39 & -86.27 & -13.67 & -25.07 & -13.67 & 0.00 & 18.10 \\
\hline Kerala & -82.01 & -78.33 & -9.63 & -64.24 & -9.63 & 26.60 & 112.56 \\
\hline MP & 0.00 & 0.00 & 0.00 & 0.00 & 0.00 & 0.00 & 0.00 \\
\hline Maharastra & -77.02 & -88.81 & -21.08 & -20.61 & -20.61 & 0.00 & 0.00 \\
\hline Manipur & 0.00 & 0.00 & 0.00 & 0.00 & 0.00 & 0.00 & 0.00 \\
\hline Meghalaya & 0.00 & 0.00 & 0.00 & 0.00 & 0.00 & 0.00 & 0.00 \\
\hline Mizoram & 0.00 & 0.00 & 0.00 & 0.00 & 0.00 & 0.00 & 0.00 \\
\hline Nagaland & 0.00 & 0.00 & 0.00 & 0.00 & 0.00 & 0.00 & 0.00 \\
\hline Odisha & -52.37 & -91.17 & -89.65 & -22.06 & -28.54 & 0.00 & 11.99 \\
\hline Rajasthan & -70.62 & -79.54 & -29.09 & -50.66 & -29.09 & 0.00 & 0.00 \\
\hline $\mathrm{TN}$ & 0.00 & 0.00 & 0.00 & 0.00 & 0.00 & 0.00 & 0.00 \\
\hline Tripura & 0.00 & 0.00 & 0.00 & 0.00 & 0.00 & 0.00 & 0.00 \\
\hline UP & -94.34 & -94.05 & -14.78 & -63.18 & -14.78 & 0.00 & 0.00 \\
\hline Uttarakhand & 0.00 & 0.00 & 0.00 & 0.00 & 0.00 & 0.00 & 0.00 \\
\hline
\end{tabular}

From the frequency distribution of Efficiency score in Table- 6 it can be inferred that DMUs like Kerala, Assam, Andhra, Chattisgarh, Manipur, Mizoram are managerially more efficient in utilizing the inputs but inappropriate scale of operation makes them scale inefficient i.e., the expansion of inputs do not give outcome as it is supposed to . hence, there is possibility that these DMUs can do better provided the state can do better provided the authority take appropriate operational policies.

Table -6: Frequency Distribution of the CCR and BCC Efficiency Scores

\begin{tabular}{|l|l|l|l|}
\hline $\mathrm{Cl}(\mathrm{CCR})$ & No. of Sates & $\mathrm{Cl}(\mathrm{BCC})$ & No. of Sates \\
\hline $0.2-0.4$ & Assam & $0.7-0.8$ & Rajasthan, Assam, Odisha, Maharastra \\
\hline $0.4-0.6$ & Kerala & $0.8-0.9$ & UP, Karnatak, Gujarat \\
\hline $0.6-0.8$ & $\begin{array}{l}\text { Rajasthan, Karnataka, Odisha, Maharastra, } \\
\text { Chattisgarh }\end{array}$ & $0.9-1.0$ & $\begin{array}{l}\text { Kerala, Andhra, Chattisgarh, Jharkhand, } \\
\text { MP, Manipur, Meghalaya, Himachal, } \\
\text { Haryana, Mizoram, Goa, Nagaland, Bihar, } \\
\text { TN, Tripura, Uttarakhand }\end{array}$ \\
\hline $0.8-1.0$ & $\begin{array}{l}\text { UP., Gujarat, Manipur, Mizoram, Andhra, } \\
\text { Jharkhand, MP, Hachal, Haryana, } \\
\text { Meghalaya, Goa, Nagaland, Bihar, TN, Tripura, } \\
\text { Uttarakhand. }\end{array}$ & \begin{tabular}{l} 
\\
\hline
\end{tabular}
\end{tabular}

There is huge possibility that these states can increase their scale of operation and could increase their performance. In case of local measure of efficiency, UP TN, Haryana and Bihar become most frequent referee for the inefficient DMU to 
become fully efficient. But in case of global comparison, Manipur and TN become the highest number of times peer DMU for the inefficient DMUs. While considering Goa, Meghalaya, Nagaland and Manipur as the reference DMUs, Manipur can use 35 of the inputs used by Meghalaya and 18 of Nagaland to become as overall efficient. Similarly, Mizoram can become overall efficient by improving the scale of its operation by using 78 of the inputs of Nagaland and little of Goa's input.

But the non-radial measure of efficiency (SBM, slack based measure) can be used (input oriented) to decompose the nonradial technical efficiency into mix efficiency (MIX) and CCR efficiency (TE) (Scale efficiency (SE) and pure technical efficiency (PTE).

$$
[\text { Input Oriented SBM }]=[\text { Radial efficiency }(T E)] *[\text { mix efficiency }(M I X)]
$$

The optimal solution $\left(\mathrm{SBM}_{\mathrm{in}}\right),\left(\rho_{i n^{*}}, \lambda^{*} s^{-*}, s^{+*}\right)$ can make $\rho_{i n^{*}}<\theta^{*} \mathrm{CCR}$ if $\theta^{*}$ shows any input mix inefficiency. If $\rho_{i n^{*}}=$ $\theta^{*} \mathrm{CCR}$ then the input oriented $\theta^{*} \mathrm{CCR}$ has zero slack for every optimal solution. This follows that the states who are in MPSS are also SBM efficient ie they have no radial and non-radial inefficiency.

The value of $\rho_{i n^{*}}=1$ shows no PTE and the full efficient states (SBM) are the states CCR efficient and achieve MPSS .The SBM input oriented efficiency score and its decomposition into PTE, MIX and SE are presented in Table- 7. As per the results, among the SBM inefficient states, the discrepancy between TE and SBM efficiency scores is more pronounced for Andhra, Assam, Chhattisgarh, Gujarat, Jharkhand, Karnataka, Kerala, Maharastra, Odisha, Rajasthan and UP.

The 12 DMUs suffering from mix inefficiency are (Assam, Kerala, Rajasthan, Chhattisgarh, Maharastra, Karnataka, Uttar Pradesh, Odisha, Gujarat, Jharkhand and Mizoram). The mix efficiency is obtained by $\frac{\rho_{\text {in }}^{*}}{\theta * C \mathrm{i}} \mathrm{i}$,e. the ratio between nonradial efficiency by radial efficiency. The results of decomposition of technical efficiency show that the low SBM score of Assam is due to combination of PTE (0.71) scale efficiency (0.49) and mix (0.51). In case of Chhattisgarh SBM (0.31) is due to mix (0.40) and $\mathrm{SE}(0.83)$. The states with low efficiency owing to high mix inefficiency are Andhra Pradesh (0.58), Assam (0.51), Chhattisgarh (0.40) Gujarat (0.50), Jharkhand (0.58), Karnataka (0.47), Kerala (0.43),Maharashtra (0.42), Odisha (0.49), Rajasthan (0.38) and UP (0.39). The low SBM states owing to mix inefficiency and scale inefficiency are Assam and Kerala. However, results show that even though AP is roughly efficient with respect to SE (0.99) and PTE $(0.91)$ that low mix (0.58) forces it to be inefficient with a low SBM score of $(0.52)$. Odisha is approximately is scale efficient but its low PTE and Mix makes the DMUs overall technically inefficient. As far as the RTS is concerned Assam and Kerala can possibly improve their overall efficiency by scaling up their activities.

Table-7: SBM Efficiency Scores under CRS and Decomposition of the Non Radial Efficiency

\begin{tabular}{|l|l|l|l|l|l|l|}
\hline DMU & $\rho_{i n^{*} \text {-CRS(SBM) }}$ & Rank & $\theta^{*}{ }_{\text {CCR }(\mathrm{TE})}$ & $\theta^{*}{ }_{\text {BCC(PTE) }}$ & MIX & SE \\
\hline Andhra & 0.52 & 14 & 0.90 & 0.91 & 0.58 & 0.99 \\
\hline Assam & 0.18 & 23 & 0.35 & 0.71 & 0.51 & 0.49 \\
\hline Bihar & 1.00 & 1 & 1.00 & 1.00 & 1.00 & 1.00 \\
\hline Chhattisgarh & 0.31 & 20 & 0.78 & 0.94 & 0.40 & 0.83 \\
\hline Goa & 1.00 & 1 & 1.00 & 1.00 & 1.00 & 1.00 \\
\hline Gujarat & 0.44 & 15 & 0.87 & 0.89 & 0.50 & 0.97 \\
\hline Haryana & 1.00 & 1 & 1.00 & 1.00 & 1.00 & 1.00 \\
\hline Himachal & 1.00 & 1 & 1.00 & 1.00 & 1.00 & 1.00 \\
\hline Jharkhand & 0.54 & 13 & 0.93 & 0.96 & 0.58 & 0.98 \\
\hline Karnataka & 0.33 & 18 & 0.70 & 0.86 & 0.47 & 0.81 \\
\hline Kerala & 0.22 & 22 & 0.51 & 0.90 & 0.43 & 0.56 \\
\hline MP & 1.00 & 1 & 1.00 & 1.00 & 1.00 & 1.00 \\
\hline Maharastra & 0.33 & 19 & 0.78 & 0.79 & 0.42 & 0.98 \\
\hline Manipur & 0.72 & 12 & 0.88 & 1.00 & 0.81 & 0.88 \\
\hline Meghalaya & 1.00 & 1 & 1.00 & 1.00 & 1.00 & 1.00 \\
\hline Mizoram & 0.77 & 11 & 0.89 & 1.00 & 0.86 & 0.89 \\
\hline Nagaland & 1.00 & 16 & 0.75 & 0.78 & 0.49 & 0.96 \\
\hline Odisha & 0.37 & 0.25 & 0.65 & 0.71 & 0.38 & 0.92 \\
\hline Rajasthan & & 1.00 & 1.00 & 1.00 & 1.00 \\
\hline & 0.00 & & & \\
\hline
\end{tabular}




\begin{tabular}{|l|l|l|l|l|l|l|} 
TN & 1.00 & 1 & 1.00 & 1.00 & 1.00 & 1.00 \\
\hline Tripura & 1.00 & 1 & 1.00 & 1.00 & 1.00 & 1.00 \\
\hline UP & 0.33 & 17 & 0.84 & 0.85 & 0.39 & 0.99 \\
\hline Uttarakhand & 1.00 & 1 & 1.00 & 1.00 & 1.00 & 1.00 \\
\hline Average & & 0.91 & & & & \\
\hline SD & & 0.17 & & & & \\
\hline
\end{tabular}

The DMUs with higher PTE are Andhra, Chattisgarh, Gujarat, Jharkhand, Kerala. But due to mix inefficiency and scale inefficiency these states could not perform well with the best performers of the country. There is huge possibility that they can increase the operation scale and consequently the mix inefficiency can be minimized.. The input output projection under the SBM input orientation with CRS assumption (Table-8) shows that Andhra can increase its PSFS by $22 \%$ despite reduction in input mix. The most important inputs reduction is for number of private unpaid schools and STSE. Karnataka could increase the PSFS by $22 \%$ and Manipur can increase PSMS by $23 \%$. The close look at the data regarding the percentage of male and female teachers in Manipur (State report card, MHRD, 2010-11) shows that it is around 18\% in both the situation. This means that the states are not equipped with quality teachers which causes under performance in the results. Majority of the SBM inefficient states do project for the reduction of the inputs such as SA, PUS and STSE. Goa becomes the most frequent peer ( 11 times) for the inefficient DMUs followed by Nagaland and Uttarakhand ( 5 times each)

Table-8 : SBM $_{\text {in }}$ Input Output Projection under CRS Assumption

\begin{tabular}{|c|c|c|c|c|c|c|c|}
\hline DMU & SA & PUS & STSE & PTR & GPTB & PSMS & PSFS \\
\hline Andhra & -52.94 & -91.32 & -91.41 & -5.43 & 0.00 & 0.00 & 21.50 \\
\hline Assam & -98.64 & -94.36 & -90.21 & -68.78 & -59.94 & 0.00 & 0.00 \\
\hline Bihar & 0.00 & 0.00 & 0.00 & 0.00 & 0.00 & 0.00 & 0.00 \\
\hline Chhattisgarh & -95.34 & -74.54 & -95.61 & -64.85 & -13.26 & 0.00 & 0.00 \\
\hline Goa & 0.00 & 0.00 & 0.00 & 0.00 & 0.00 & 0.00 & 0.00 \\
\hline Gujarat & -57.47 & -91.56 & -95.12 & -35.53 & 0.00 & 0.00 & 0.14 \\
\hline Haryana & 0.00 & 0.00 & 0.00 & 0.00 & 0.00 & 0.00 & 0.00 \\
\hline Himachal & 0.00 & 0.00 & 0.00 & 0.00 & 0.00 & 0.00 & 0.00 \\
\hline Jharkhand & -90.22 & -44.41 & -87.60 & -9.61 & 0.00 & 0.00 & 0.00 \\
\hline Karnataka & -97.96 & -97.06 & -97.62 & -34.33 & -9.58 & 0.00 & 21.65 \\
\hline Kerala & -98.32 & -89.11 & -84.63 & -74.52 & -45.90 & 1.43 & 0.00 \\
\hline MP & 0.00 & 0.00 & 0.00 & 0.00 & 0.00 & 0.00 & 0.00 \\
\hline Maharastra & -96.44 & -97.78 & -96.95 & -36.98 & -8.47 & 0.00 & 0.00 \\
\hline Manipur & -55.63 & -55.33 & -18.76 & 0.00 & -11.01 & 22.52 & 0.00 \\
\hline Meghalaya & 0.00 & 0.00 & 0.00 & 0.00 & 0.00 & 0.00 & 0.00 \\
\hline Mizoram & -10.71 & -46.20 & -21.80 & -22.21 & -12.65 & 0.00 & 0.00 \\
\hline Nagaland & 0.00 & 0.00 & 0.00 & 0.00 & 0.00 & 0.00 & 0.00 \\
\hline Odisha & -72.01 & -92.75 & -92.21 & -24.01 & -32.97 & 0.00 & 0.00 \\
\hline Rajasthan & -89.34 & -95.74 & -95.25 & -68.15 & -24.27 & 0.00 & 0.00 \\
\hline TN & 0.00 & 0.00 & 0.00 & 0.00 & 0.00 & 0.00 & 0.00 \\
\hline Tripura & 0.00 & 0.00 & 0.00 & 0.00 & 0.00 & 0.00 & 0.00 \\
\hline UP & -95.42 & -96.05 & -63.07 & -66.72 & -14.14 & 0.00 & 0.00 \\
\hline Uttarakhand & 0.00 & 0.00 & 0.00 & 0.00 & 0.00 & 0.00 & 0.00 \\
\hline
\end{tabular}

\section{CONCLUSION}

This paper has attempted to decompose the non-radial technical efficiency in terms of a scalar called SBM of efficiency (input Oriented) of the performances of 23 states of India in the $10^{\text {th }}$ class examination. Applying CCR, BCC and SBM 
models for five inputs and two outputs obtained from the Statistics of school education, 2010-11 (MHRD, Govt. of India), the efficiency scores were computed and the SBM efficiency scores were decomposed into technical efficiency, pure technical efficiency, scale efficiency and mix efficiency. As per the result, out of 23 DMUs10 DMUs fully SBM efficient with score equals to 1 and hence they are TE, PTE and Scale efficient implying most productive scale size. That is the input ratios of these DMUs are in proportion to their price ratio. But more than half of the DMUs (13) are inefficient with Assam being the lowest performer (0.18) followed by Kerala (0.22), Rajasthan (0.25) and Chhattisgarh (0.31). The DMUs with low SBM score due to PTE and MIX are Assam, Karnataka, Maharastra, Odisha, Rajasthan and UP. The DMUs having low score due to low PTE and low SE are Assam and Karnataka. The DMUs with low SBM score due to low PTE, MIX and SE are Assam and Karnataka. The study emphasizes, merger of small private schools, increase in the appointment of both trained male and female teachers, Creation of more class rooms. One important implication of the result is that the state should focus more on the giving special coaching to the SC/ST students and the girl students especially in English, math and science. Many of the parents of these students in the rural area are incapable of teaching them; they just send them to school in the name of giving education without any care. It has been experienced that in rural areas even girls are talented than the boys, they have been directly or indirectly informed that their education will discontinue very shortly. Hence, they become morally disheartened and perform less than their potential. Therefore, the state should focus. Rural schools should be equipped with proper school infrastructure, quality and trained teacher, facilities for extra coaching in the school level and restriction of opening schools without proper facilities such as teacher, building, proper environment and communication facilities.

\section{REFERENCES}

[1] Abbott, M., and C. Doucouliagos (2003), "The Efficiency of Australian Universities: A Data Envelopment Analysis." Economics of Education Review Volume 22, No. 1, pp. 89-97.

[2] AFONSO, A; SANTOS, M.(2004) Students and Teachers A DEA Approach to the Relative Efficiency of Portuguese Public Universities. Technical University of Lisbon, series Working Papers n. 2005/07.

[3] Ahn, Taesik and L.M. Seiford (1993), Sensitivity of DEA models and Variable Sets in a Hypothesis Test Setting: the Efficiency of University Operations, in Yuji ljiri (ed.) Creative and Innovative Approaches to the Science of Management. Westport CT: Quorum Books.

[4] Ahn, Taesik (1987), Efficiency and Related Issues in Higher Education: A Data Envelopment Analysis Approach, Doctoral dissertation, The University of Texas at Austin, Austin, TX.

[5] Ahn, Taesik., Abraham Charnes., and William W. Cooper (1988), "Some Statistical and DEA Evaluations of Relative Efficiencies of Public and Private Institutions of Higher Learning," Socio-Economic Planning Sciences, Volume 22, Number 6, pp. 259-269.

[6] Ahn, Taesik, Victor Arnold, Abraham Charnes, and William W. Cooper (1998), "DEA and Ratio Efficiency Analyses for Public Institutions of Higher Learning in Texas," Research in Governmental and Nonprofit Accounting, Volume 5, pp. 165-185.

[7] Avkiran, Necmi K. (2001), "Investigating Technical and Scale Efficiencies of Australian Universities Through Data Envelopment Analysis," Socio-Economic Planning Sciences, Volume 35, pp. 57-80.

[8] Beasley, J.E. (1995), "Determining Teaching and Research Efficiencies," Journal of the Operational Research Society, Volume 46, pp. 441-452.

[9] BELLONI, J. A. Uma. (2000) Metodologia de Avaliação da Eficiência Produtiva de Universidades Federais Brasileiras. Tese (Engenharia de Produção), Programa de Pós-Graduação em Engenharia de Produção, Universidade Federal de Santa Catarina,.

[10] Breu, Theodore. M. and Raymond, L. Raab. (1994), "Efficiency and Perceived Quality of the Nation's "Top 25" National Universities and National Liberal Arts Colleges: An Application of Data Envelopment Analysis to Higher Education," Socio-Economic Planning Sciences, Volume 28, pp. 33-45.

[11] Burton, M. P. and Phimister, E.(1995) "Core Journals:Area appraisal of the Diamond List" ,The Economic Journal, Vol.105,361-373.

[12] Charnes, Abraham, William W. Cooper, and E.L. Rhodes (1978), "Measuring Efficiency of Decision Making Units," European Journal of Operational Research, Volume 2, pp. 429-444.

[13] Charnes, Abraham, William W. Cooper, and E.L. Rhodes (1981), "Evaluating Program and Managerial Efficiency: An Application of Data Envelopment Analysis to Program Follow Through," Management Science, Volume 27, pp. 668-697.

[14] Cooper, W.W., Lawrence, M. S. and Tone K. (2000) Data Envelopment Analysis : A Comprehensive Text with Models, Applications References and DEA Solver Software, Kluwer Academic Publisher, NY.

[15] Emrouznejad, Ali and E. Thanassoulis (1996), An Extensive Bibliography of Data Envelopment Analysis (DEA) Volumes 1-5, Working Papers, Warwick Business School. 
[16] Charnes, Abraham, William W. Cooper, and E.L. Rhodes (1978), "Measuring Efficiency of Decision Making Units," European Journal of Operational Research, Volume 2, pp. 429-444.

[17] Charnes, Abraham, William W. Cooper, and E.L. Rhodes (1981), "Evaluating Program and Managerial Efficiency: An Application of Data Envelopment Analysis to Program Follow Through," Management Science, Volume 27, pp. 668-697.

[18] Coelli, Tim, D.S. Prasada Rao, and George E. Battese (1998), An Introduction to Efficiency and Productivity Analysis. Boston: Kluwer Academic Publishers.

[19] Emrouznejad, Ali and E. Thanassoulis (1996), An Extensive Bibliography of Data Envelopment Analysis (DEA) Volumes 1-5, Working Papers, Warwick Business School.

[20] FORSUND, F. R; KALHAGEN, K, O. Efficiency and Productivity of Norwegian Colleges. Oslo University, Department of Economics, series Memorandum n. 11, 1999.

[21] FLEGG, A. T; ALLEN D.O; FIELD K. \& THURLOW, T.W..( 2003) Measuring the Efficiency and Productivity of British Universities: An Application of DEA and the Malmquist Approach. University of the West of England, Department of Economics, series Discussion Papers n. 304,.

[22] Haksever, C \& Muragishi, Y (1998)"'Measuring value in MBA programmes" Education Economics, 6(1) pp11-25

[23] Johnes, Jill (2006). "Data Envelopment Analysis and its Application to the Measurement of Efficiency in Higher Education." Economics of Education Review Volume 25, No. 3, pp. 273-288.

[24] JOUMADY, O; RIS, C.(2005) Performance in European Higher Education: A Non-Parametric Production Frontier Approach. Journal of Education Economics, 2. ed, p. 189-205,

[25] Ng, Ying Chu, and Sung Ko Li (2010), "Measuring the Research Performance of Chinese Higher Education Institutions: An Application of Data Envelopment Analysis." Education Economics Volume 8, No. 2, pp. 139 156.

[26] OLIVEIRA, C. E. M; TURRIONI, J. B. (2005) Avaliação de Desempenho de Instituições Federais de Ensino Superior Através da Analise por Envoltória de Dados (DEA). In ENGEP

[27] Rhodes, E.L. and L. Southwick Jr. (1986), Determinants of efficiency in public and private universities, Mimeo, School of Environmental and Public Affairs, Indiana University, Bloomington, IN.

[28] Kulshreshtha, P. \& Nayak,T.K.(2015). "Efficiency of Higher Technical Educational Institutions in India" .Archive of Business Research,3(1) 94-122.

[29] SARRICO, C. S. (1997)" Data envelopment analysis and university selection." Journal of the Operational Research Society, v. 48, p. 1163-1177.

[30] SOUZA, H. R.; RAMOS. F.S. (1997)" Performance Evaluation in The Public Sector: An Application of Efficiency Measures to Brazilian Federal Higher Education Institutions," Tenth World Productivity. pp. 430450, 1997.

[31] Tone, K. (1997) "DEA with controllable category levels," in Proceedings of the 1997 Spring National Conference of the Operation Research Society of Japan, pp. 126-27.

[32] Tone, K. (2001) " On returns to Scale under Weight Restrictions in Data Envelopment Analysis," Journal of Productivity Analysis, 16, pp.31- 47. 